\title{
Quantum Chemical Studies on the Corrosion Inhibition of Some Hector Bases on Mild Steel in Acidic Medium
}

\author{
MAJID KHODAEI-TEHRANI* and ALI NIAZI \\ Department of Chemistry, Arak branch, Islamic Azad University, Arak, Iran. \\ ${ }^{*}$ Corresponding author E-mail: m.khodaei.tehrani@gmail.com \& m-khodaei92@iau-arak.ac.ir
}

http://dx.doi.org/10.13005/ojc/310150

(Received: November 29, 2014; Accepted: January 10, 2015)

\begin{abstract}
The density functional theory (DFT) at the B3LYP/6-31G $(d, p)$ basis set level method were performed on three hector bases used as corrosion inhibitors; namely, 3-anilino-5-imino-4-phenyl1, 2,4-thiadiazoline (AIPT), 3-anilino-5-imino-4-tolyl-1, 2,4-thiadiazoline (AITT), and 4-(4chlorophenyl)-5-imino-N-phenyl-4,5-dihydro-1,2,4-thiadiazol-3-amine (AICT). They were used as corrosion inhibitors for mild steel in acidic medium in order to determine the relationship between molecular structure and their corresponding inhibition efficiency (\%IE). The results of the quantum chemical calculations and experimental \%IE were subjected to correlation analysis. This indicates that their inhibition effects are closely related to the highest occupied molecular orbital energy $\left(E_{\text {номо }}\right)$, the lowest unoccupied molecular orbital energy $\left(E_{\text {Luм⿰ }}\right)$, the energy gap $(\Delta E)$, the hardness $(\eta)$, the softness $(\sigma)$, the electronegativity $(\chi)$, and the fraction of electrons transferred from the inhibitor molecule to the metal surface $(\Delta N)$. In addition, the local reactivity has been analyzed through the Fukui function. Two QSAR equations were developed and used to predict the corrosion inhibition efficiency for hector bases.
\end{abstract}

Key words: hector bases, Inhibition of corrosion, Quantum chemical parameters, Fukui function.

\section{INTRODUCTION}

The use of corrosion inhibitor is one of the most effective and highly cost-effective measures to mitigate corrosion of mild steel in acidic media ${ }^{1-}$ ${ }^{4}$. Most of acid corrosion inhibitors are organic compounds containing electronegative atoms (such as sulfur, phosphorus, Nitrogen, and oxygen, etc.), the unsaturated bonds (such as, double bonds or triple bonds, etc.) and the plane conjugated systems including all kinds of aromatic cycles ${ }^{5-11}$.It has been reported that the best efficiencies of $\mathrm{N}$ containing inhibitors have been shown in hydrochloric acid ${ }^{12}$. The adsorption of the examined thiadiazole molecules can occur as a result of the formation of links between the d-orbital of iron atoms, which involve the displacement of water molecules from the metal surface by the lone $\mathrm{sp}^{2}$ electron pairs present on the $\mathrm{N}$ atoms of both the heterocyclic rings and $\mathrm{S}$ atom of thiadiazole ring. 
Quantum chemical calculations have been widely used to study the reaction mechanism of corrosion inhibition or even predict with confidence some experimentally unknown properties ${ }^{13-16}$.

These studies have been successfully performed to link the corrosion inhibition efficiency and have provided specific information about charge distribution, molecular structure, the frontier molecular orbital energy ( $\mathrm{E}_{\text {номо }}$, $\mathrm{E}_{\text {Lumo }}$, etc.) and adsorption processes of corrosion inhibitors.

The objective of this work is to investigate the dependence of inhibition efficiency of three hector bases used as corrosion inhibitors namely 3-anilino-5-imino-4-phenyl-1, 2,4-thiadiazoline (AIPT), 3-anilino-5-imino-4-tolyl-1, 2,4-thiadiazoline (AITT), and 4-(4-chlorophenyl)-5-imino-N-phenyl4,5-dihydro-1,2,4-thiadiazol-3-amine (AICT) and used as corrosion inhibitors towards mild steel in hydrochloric acid with their calculated quantum chemical parameters in the neutral forms using statistical tool .These inhibitors have been reported by M.A.Quraishi et al. ${ }^{17}$.The study has been conducted by polarization measurements, impedance techniques and weight loss measurements. Using both electrochemical polarization and weight loss techniques, and found that all hector bases reduce the corrosion of steel.

\section{Computational method}

The structures optimized by using: DFT (density functional theory) with The Becke's threeparameter hybrid functional ${ }^{18}$ was combined with the Lee, Yang, and Parr (LYP) correlation functional ${ }^{19}$ and denoted as B3LYP theory and was employed in the DFT calculations using 6-31G $(d, p)$ basis set. In all cases, the quantum chemical calculations were performed with complete geometry optimizations are implemented by means of Gaussian 03 (Review B.05) program software package $^{20}$.

According to Koopman's theorem ${ }^{21}$, Frontier molecular orbitals (HOMO and LUMO) could be used to predict the adsorption centers of the inhibitors. For the simplest transfer of electrons, adsorption should occur at the part of the molecule where the softness, $\sigma$, which is a local property, has the highest value. The $\mathrm{E}_{\text {номо }}$ and $\mathrm{E}_{\mathrm{LumO}}$ of the inhibitor molecule are related to the electron affinity, A, and the ionization potential, I, respectively, are given by: $I=-E_{\text {номо }}$ and $A=-E_{\text {LUмо }}$.

Absolute electronegativity, $\chi$, and absolute hardness, $\eta$, of the Inhibitor molecule were calculated by using the values of $I$ and $A$ and given by: $Z=\frac{I+A}{2}$ and $\eta=\frac{I-A}{2}$. And the global softness, $\sigma$, is the inverse of the global hardness: $\sigma-\frac{1}{\eta}$.

Thus the fraction of electrons transferred from the inhibitor to metallic surface, $\Delta N$, as follow ${ }^{22}$ :

$$
\Delta N=\frac{\chi_{F e}-\chi_{i n h}}{2\left(\eta_{F e}+\eta_{i n h}\right)}
$$

\section{RESULTS AND DISCUSSION}

Quantum chemical calculations were carried out to research the effect of Geometric and electronic structural parameters on the inhibition efficiency of inhibitors and powerful tools for studying their adsorption mechanisms on the metal surface ${ }^{23}$ The optimized molecular structures with minimum energies obtained from the calculations are given in Fig. 1.

Quantum chemical parameters obtained from the calculations which are responsible for the inhibition efficiency of inhibitors, such as the energies of highest occupied molecular orbital $\left(E_{\text {номо }}\right)$, energy of lowest unoccupied molecular orbital $\left(\mathrm{E}_{\text {LUMO }}\right)$, the separation energy $\left(\mathrm{E}_{\text {LUмо }}-\mathrm{E}_{\text {номо }}\right)$, $\Delta \mathrm{E}$, representing the function of reactivity, the net charge on the functional group, dipole moment, $\mu$, global hardness $(\eta)$, softness,$(\sigma)$, and the fraction of electrons transferred from the inhibitor to iron surface $(\Delta N)$ for the neutral inhibitors are collected in Table 2 .

The hector bases may adsorb on the metal surface in the form of neutral molecules involving the displacement of water molecules from the metal surface and sharing of electrons between the nitrogen and sulfur atoms in the hector base molecule and the metal surface. 


\section{Neutral inhibitor}

Frontier molecular orbitals (HOMO and LUMO) may be used to predict the adsorption centers and involved in the activity properties of the inhibitor molecule. The higher the energetic level (HOMO) of the inhibitor, the greater the trend of offering electrons to unoccupied orbital of the iron metal, and the higher the corrosion inhibition efficiency for iron in $\mathrm{HCl}$ acid solutions; if the energy of HOMO level was determined for the inhibitor properties, the ranking of the compounds should be:
This agrees well with the experimental observations. Another parameter of the molecular structure is energetic level of (LUMO), in addition, the lower the LUMO energy, the easier the acceptance of electrons from metal surface, the calculations also shows that AIPT has the lowest $\mathrm{E}_{\text {LUMO }}$, so it has the greatest ability to interact with the metal surface. If the energy of LUMO level was determined for the inhibitor properties, the ranking of the compounds should be:

AICT > AITT >AIPT; $\mathrm{E}_{\text {LUMO }}$

AICT $>$ AITT $>$ AIPT, $\mathrm{E}_{\text {Hомо }}$

Table 1: Names, molecular structure, the abbreviation and atom numbering of the inhibitors investigated<smiles>N=c1snc(Nc2ccccc2)n1-c1ccccc1</smiles><smiles>CC=C(C)n1c(Nc2ccccc2)nsc1=NC</smiles><smiles></smiles>

Table 2: The calculated quantum chemical parameters for the neutral inhibitors

\begin{tabular}{lccccccccc}
\hline & $\mathbf{E}_{\text {номо }}$ & $\mathrm{E}_{\text {LUмо }}$ & $\Delta \mathrm{E}$ & $\boldsymbol{\eta}$ & $\boldsymbol{\sigma}$ & $\boldsymbol{\chi}$ & $\boldsymbol{\mu}$ & $\boldsymbol{\Delta}$ & $\%$ \\
\hline AIPT & -5.558 & -0.808 & 4.755 & 2.377 & 0.421 & 3.181 & 5.625 & 0.803 & 68.5 \\
AITT & -5.516 & -0.707 & 4.809 & 2.404 & 0.416 & 3.112 & 5.991 & 0.808 & 74.8 \\
AICT & -3.481 & 1.107 & 4.589 & 2.294 & 0.436 & 1.187 & 2.329 & 1.26 & 79.7 \\
\hline
\end{tabular}


Table 3: The condensed Fukui functions on the atoms of the studied compounds

\begin{tabular}{|c|c|c|c|c|c|c|c|c|c|c|c|}
\hline \multicolumn{4}{|c|}{ AIPT } & \multicolumn{4}{|c|}{ AITT } & \multicolumn{4}{|c|}{ AICT } \\
\hline Atom & $f$ & $f^{+}$ & charge & Atom & $f$ & $f^{+}$ & charge & Atom & $f$ & $f^{+}$ & charge \\
\hline S1 & 0.14 & 0.253 & 0.337 & S1 & 0.197 & 0.232 & 0.355 & S1 & 0.243 & 0.281 & 0.311 \\
\hline N2 & 0.053 & 0.072 & -0.563 & N2 & -0.616 & 0.071 & -0.563 & N2 & -0.338 & -0.188 & $8-0.302$ \\
\hline N4 & -0.028 & 0.016 & -0.533 & N4 & -0.508 & 0.017 & -0.534 & N4 & 0.224 & -0.292 & $2-0.228$ \\
\hline N6 & 0.043 & 0.099 & -0.579 & N6 & -0.622 & 0.098 & -0.579 & N6 & -0.355 & -0.157 & $\begin{array}{ll}7 & -0.322\end{array}$ \\
\hline N7 & -0.004 & 0.138 & -0.638 & N7 & -0.634 & 0.036 & -0.638 & N7 & 0.283 & -0.306 & $6-0.294$ \\
\hline
\end{tabular}

The trend across structures in the $\mathrm{E}_{\text {LuMO }}$ of the compounds is not in good agreement with the trend in the inhibition efficiencies of the inhibitors.

The separation energy, $\left(\Delta \mathrm{E}=\mathrm{E}_{\text {LUMO }}-\mathrm{E}_{\text {Hомо }}\right)$ is another important factor as a function of reactivity of the inhibitor molecule towards the adsorption on metallic surface. As $\Delta \mathrm{E}$ decreases, the reactivity of the molecule increases leading to increase the inhibition efficiency of the molecule i.e. a molecule with a low energy gap is more polarizable and low kinetic stability and is generally associated with the high chemical activity and is named soft molecule ${ }^{24}$. The results obtained from quantum chemical calculation are listed in Table 2. The calculations indicate that AICT has the lowest value which means the highest reactivity among the other inhibitors. The order of reactivity in this case will be: AIPT >AITT >AICT; $(\Delta \mathrm{E})$

The number of electrons transferred $(\Delta \mathrm{N})$ was also calculated depending on the quantum chemical method as in Eq. (1).Values of $\Delta \mathrm{N}$ showed inhibition effect resulted from electrons donation
Using a theoretical $\chi$ value of $7 \mathrm{eV} / \mathrm{mol}$ according to Pearson's electronegativity scale ${ }^{25}$ and $\eta$ value of $0 \mathrm{eV} / \mathrm{mol}$ for iron atom ${ }^{21}$, According to Lukovits's study $^{26}$, the inhibition efficiency increased with increasing electron-donating ability at the metal surface. In this study, the three selected organic compounds will be expected to inhibit the iron corrosion through donations of electrons to the iron surface that will be the electron acceptor as indicated in Table 2.

The order of $\Delta \mathrm{N}$ is presented as follows; AICT >AITT >AIPT, and the order is the same as in the values of the experimental corrosion inhibition efficiency (\%IE).

The dipole moment $(\mu)$ is an index that can also be used for the prediction of the direction of a corrosion inhibition process and provides information on the polarity of the molecule and it is also a good reactivity indicator. The dipole moment is a good reactivity indicator and also is related to the distribution of electrons in a molecule ${ }^{27}$. the literature is variable over the use of $\mu$ as a predictor
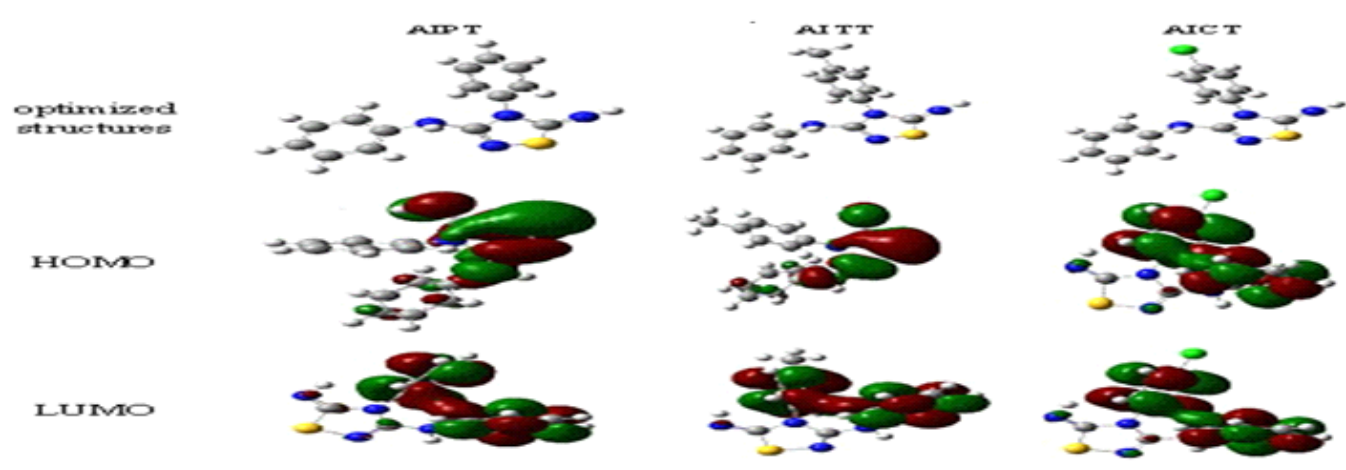

Fig. 1: The optimized molecular structures, HOMO and LUMO of the neutral inhibitor molecules using DFT/B3LYP/6-31G (d p) 
for the direction of a corrosion inhibition reaction, it is agreed that the adsorption of polar compounds possessing high dipole moments on the metal surface should lead to better inhibition efficiency ${ }^{28,}$ ${ }^{29}$ and should lead to worse inhibition efficiency but on the other hand, a survey of literature reveals that the dipole moment does not correlate well with the corrosion inhibition efficiencies of the inhibitors ${ }^{30}$. In the current work, the trend across structures in the dipole moment of the compounds is not in good agreement with the trend in the inhibition efficiencies of the inhibitors.

Pearson presented the quantities of electronic hardness $(\eta)$ and softness $(\sigma)$ in his hardsoft-acid-base principle (HSAB) ${ }^{31}$ The species are classified as soft (hard) if their valence electrons are easy (hard) to polarize or to remove and a hard molecule has a large energy gap, and a soft molecule has a small energy gap. According to this theory, soft acids interact preferentially with soft bases and hard acids interact preferentially with hard bases. Metals are generally considered to be soft acid; consequently they would like interact with inhibitors that have high $\sigma$ values and low $\eta$ values ${ }^{32}$, ${ }^{33}$. The $\sigma$ values for the investigated compounds follow the trend AICT >AITT >AIPT, which is in good agreement with experimentally determined inhibition efficiency of the inhibitors.

The Table 2 shows the order of electronegativity as AIPT> AITT> AICT. Hence an increase in the difference of electronegativity between the metal and the inhibitor is observed in the order AICT >AITT >AIPT. According to Sanderson's electronegativity equalization principle ${ }^{34}$, the electron flow happens from the molecule with the low electronegativity towards that with a higher value, until the chemical potentials are the same. AICT with a high electronegativity and low difference of electronegativity quickly reaches equalization and hence low reactivity is expected which in turn indicates low inhibition efficiency.

\section{Local Reactivity}

Fukui functions proposed by Parr and Yang $^{35}$, as measurement of local reactivity of the molecules indicative of the reactive regions and the nucleophilic and electrophilic behavior of the molecule. The Fukui function $f_{k}$ is defined as the first derivative of the electronic density $\overrightarrow{\rho(r)}$ with respect to the number of electrons $\mathrm{N}$ in a constant external

$$
\begin{aligned}
& \text { potential } v(\vec{r})^{36} \text { : } \\
& f_{k}=\left(\frac{\partial \rho(\vec{r})}{\partial N}\right)_{v(\vec{r})}
\end{aligned}
$$

Yang and Mortier ${ }^{37}$ proposed that Fukui functions can be written:

$$
\begin{aligned}
& f_{k}^{+}=q_{k}(N+1)-q_{k}(N) \quad \text { (for nucleophilic attack) } \\
& f_{k}^{-}=q_{k}(N)-q_{k}(N-1) \quad \text { (for electrophitic attack) }
\end{aligned}
$$

Where $q_{k}(N), q_{k}(N+1)$ and $q_{k}(N-1)$ are determined as the atomic charges of the neutral, anionic and cationic species, respectively.

The $f_{k}^{+}$measures the changes in density when the molecule gains electrons, and it corresponds to reactivity with respect to nucleophilic attack. The site for nucleophilic attack will be the place where the value of $f_{k}^{+}$is a maximum. On the other hand, the site for electrophilic attack is controlled by the value of $f_{k}$-and the highest value of $f_{k}$ corresponds to a possible site for an electrophilic attack.

As can be seen from Table 3, the nitrogen atoms contain the surplus of negative charge. Among the nitrogen atoms, the highest negative charge is located on the N7 in AIPT and AITT. It is confirmed that the more negative the atomic charges of the adsorbed center, the more easily the atom donates its electrons to the unoccupied orbital of metal. Therefore, these atoms contain the surplus of negative charge should be the active adsorption sites. On the other hand, the sulfur atom contains the surplus of positive charge. The highest positive charge among the sulfur atoms related to sulfur atom of AICT. Thus, the N2, N4, N6 and N7 may be the most active adsorption sites. It is thought that the more positive the atomic charge leads to more easily the atom acceptance of metal electrons to the unoccupied orbital of sulfur atom. Further analysis of fukui functions (Table 3 ) show that the 
$\mathrm{N} 1$ and N3 are the most susceptible sites for the electrophilic attacks as they present the highest values The highest value of and the most susceptible sites for the electrophilic attacks are S1 and N2 in AIPT and AITT and S1 in AICT.

\section{QSAR study}

In this investigation, quantitative structure and activity relationship (QSAR) has also been used to correlation between quantum chemical parameters and the observed inhibition efficiency of the studied inhibitors. The experimental determination the adsorption of the studied inhibitors on the mild steel surface follows Langmuir's adsorption isotherm. Therefore, it is practical to use the linear and the non-linear mathematical models proposed by Lukovit's et al. ${ }^{38}$, in order to correlate the observed inhibition efficiency to the calculated quantum chemical parameters. The linear model approximates inhibition efficiency ( $\mathrm{IE}_{\mathrm{cal}} \%$ ) has the form:

$$
I E_{c a l} \%=A x_{j} C_{i n h i}+B
$$
employed:

The non-linear model has been

$$
I E_{c a l} \%=\frac{\left(A x_{j}+B\right)}{1+\left(A x_{j}+B\right) C_{\text {inhi }}} \times 100
$$

Where $\mathrm{IE}_{\mathrm{cal}} \%$ is the inhibition efficiency, $\mathrm{A}$ and $B$ are the regression coefficients determined by regression analysis, $X_{i}$ is a quantum chemical index characteristic for the molecule (j) and $\mathrm{C}_{\mathrm{inh}, \mathrm{i}}$ denotes the concentration of the inhibitor in experiment $\mathrm{i}$.
The best linear and non-linear equations resulting were using DFT/B3LYP/6-31G $(d, p)$ for from the combination of the $\mathrm{E}_{\text {Hомо }}, \mathrm{E}_{\mathrm{LUMO}}, \Delta \mathrm{E}$ and $\Delta \mathrm{N}$ parameters have these forms;

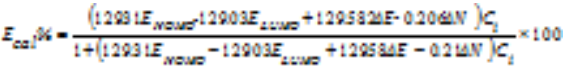

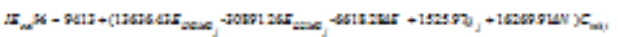

The correlation coefficient values $\left(R^{2}\right)$ were obtained for the linear, resistance and nonlinear models were 0.926 and 0.634 . The best equation resulting from these models was obtained from linear model.

\section{CONCLUSION}

The correlation between the quantum chemical parameters and inhibition efficiency of some hector bases was investigated using DFT/ B3LYP calculations. The inhibition efficiency of the inhibitor is closely related to the quantum chemical parameters, $\mathrm{E}_{\text {номо }}, \omega, \sigma, \chi$, and $\Delta \mathrm{N}$ for the neutral inhibitors and no significant relationship was found with parameters, $\mu$ and $E_{\text {LUMO }}$. It was shown by fukui functions that the $\mathrm{N} 1$ and $\mathrm{N} 3$ atoms are the most susceptible sites for the electrophilic attacks and the most susceptible sites for the electrophilic attacks are $\mathrm{S} 1$ and $\mathrm{N} 2$ atoms in AIPT and AITT molecules and $\mathrm{S} 1$ atom in AICT molecule. The inhibition efficiency of the inhibitors is closely related to the quantum chemical parameters and the linear model presented the best correlation with experimental data. The prediction of corrosion efficiencies of these compounds elegantly matched to the experimental measurements.

\section{REFERENCES}

1. Bentiss, F.; Lebrini, M.; Lagrenee, M. Corros. Sci. 2005, 47, 2915-2931

2. Aljourani, J; Raeissi, K.; Golozar, M.A. Corros. Sci. 2009, 51, 1836-1843

3. Obot, I.B.; Obi-Egbedi, N.O.; Umoren, S.A. Corros. Sci. 2009, 51, 276-282

4. Zheludkevich, M.L.; Yasakau, K.A.; Poznyak, S.K.; Ferreira, M.G. Corros. Sci. 2005, 47, 3368-3383
5. Wang, H.; Liu, R.; Xin, J. Corros. Sci. 2004, 46, 2455-2466

6. Khaled, K.F.; Babic-Samardzija, K.; Hackerman, N. J. Appl. Electrochem. 2004, 34, 697-704

7. Hosseini, M.; Mertens, S.; Ghorbani, M.; Arshadi, M. Mater. Chem. Phys. 2003, 78, 800-808

8. Khaled, K.F.; Babic-Samradzija, K.; 
Hackerman, N. Electrochim. Acta 2005, 50, 2515-2520

9. Abd El-Rehim, S.S.; Ibrahim, M.A.M.; Khaled, K.F. J. Appl. Electrochem 1999, 29, 593-599

10. Bentiss, F.; Lagrenee, M.; Traisnel, M.; Hornez, J.C. Corros. Sci. 1999, 41, 789-803

11. Sherif, E; Park, S.M. J Electrochem Soc.2005, 152, 428-433

12. Schmitt, G. Br. Corros. J. 1984, 19, 165-176

13. Awad, M. K.; Mustafa, M. R.; Abo Elnga, M. M. J. Mol. Struct. (Theochem) 2010, 959, 66-74

14. Kosari, A.; Momeni, M.; Parvizi, R.; Zakeri, M.; Moayed, M.H.; Davoodi, A.; Eshghi, H. Corros. Sci. 2011, 53, 3058-3067.

15. Khaled, K.F.; Amin, M.; Corros. Sci. 2009, 51, 1964-1975

16. Growcock, F.B. Corros. Sci. 1989 45, 10031007

17. Quraishi, M.A.; Sardar, R.; J. Appl. Electrochem. 2003, 33, 1163-1168.

18. Becke, A.D. J. Chem. Phys. 1993, 98, 5648 5652

19. Lee, C.; Yang, W.; Parr, R.G. Phys. Rev. B: Condens. Matter 1988, 37, 785-789

20. Frisch, M.J. et al. Gaussian 03, Revision B.05, Gaussian, Inc., Wallingford, CT, 2004.

21. Sastri, V.S.; Perumareddi, J.R. Corrosion, 1996, 671, 617-622

22. Pearson, R.G. Inorg. Chem. 1988, 27, 734740.

23. Fang, J; Li, J.J. Mol. Struct. (Theochem) 2002, 593, 179-185

24. Fleming, Frontier Orbitals and Organic
Chemical Reactions, John Wiley and Sons, New York, 1976.

25. Pearson, R.G. Proc. Nati. Acad. Sci. 1986, 83, 8440-8441

26. Lukovits, I.; Kalman, E.; Zucchi, F. 2001, 57, 3-8

27. Issa, R.M.; Awad, M.K.; Atlam, F. M. Appl. Surf. Sci. 2008, 255, 2433-2441

28. Ju, H.; Kai, Z.P.; Li, Y. Corros. Sci. 2008, 50, 865-871

29. Popova, A.; Christov, M.; Raicheva, S.; Sokolova, E. Corros. Sci. 2004, 46, 13331350

30. Ebenso, E.E. Bull. Electrochem. 2003, 19, 209-216

31. Koch, E, Propellants Explos. Pyrotech. 2005, 30, 209-215

32. Obi-Egbedi, N.O.; Obot, I.B.; El-Khaiary, M.I.; Umoren, S.A.; Ebenso, E.E. Int. J. Electrochem. Sci. 2011, 6, 5649-5675

33. Li, W.; Zhao, X.; Liu, F.; Deng, J.; Hou, B. Mater. Corros. 2009, 60, 287-293

34. Geerlings, P.; De Proft, F. Int. J. Mol. Sci. 2002, 3, 276-309

35. Parr, R.G.; Yang, W. J. Am. Chem. Soc. 1984, 106, 4049-4050

36. De Proft, F.; Martin, J.M.L.; Geerlings, $P$. Chem. Phys. Lett. 1996, 256, 400-408

37. Yang, W.; Mortier, W.J. J. Am. Chem. Soc. 1986, 108, 5708-5711

38. Lukovits, I.; Kálmán, E.; Pálinkás, G. Corrosion 1995, 51, 201-205. 